\title{
Mucoperosteum of the Palate - An Ideal and Versatile Reconstructive Tool
}

\section{Dr. Manjunath $\mathrm{KN}^{*}$ and Dr. Veena P Waiker}

Department of Plastic and Reconstructive surgery, Ramaiah Medical College, M S Ramaiah Nagar, Bengaluru, Karnataka, India

\begin{abstract}
Background: Palate is a complex structure separating oropharynx and nasopharynx. However reconstruction of the defects of palate is much simpler because of the available versatile mucoperiosteal flaps. Here we present our experience of palatal mucoperiosteal flap used in different situation.
\end{abstract}

Methods: 10 patients of palatal as well as buccal mucosa defects were reconstructed using either free or pedicled mucoperiosteum.

Results: All patients recovered well. No flap loss or secondary procedures were required.

Conclusion: Palate is a complex structure both functionally and anatomically. Success in Reconstruction of the palatal defects depends on creation of good nasal as well as buccal mucosal lining. The rich vascular macronet in the palatal mucosa makes it an ideal donor site for local reconstruction. The mucoperiosteum harvested either as a free graft or as pedicled flap serves the purpose well leaving no donor site deformity.

Keywords: Palate; Reconstructive tool; Mucoperiosteum; Cleft palate

\section{Introduction}

Palate is a complex structure both anatomically and functionally, comprising of bone, muscle and mucosa. Functionally both hard and soft palate, together serve as one unit to separate nasopharynx and oropharynx, such separation plays an important role in articulation of speech and deglutition. So, the main goal of palatal reconstruction is separation of oropharynx from the nasopharynx [1]. Although the structure and function of palate (both hard and soft) is complex, reconstruction of defects of palate is much simpler because of locally available the versatile mucoperiosteal flaps. The mucoperiosteum over the bony palate is highly vascular and can be easily harvested as flap. The bare bony frame work epithelises early and leaves no donor site deformity. All these features make it the best available tissue for reconstruction of local as well as adjacent buccal mucosa.

\section{Materials and Methods}

10 patients of palatal as well as buccal mucosa defects were reconstructed using either free or pedicled mucoperiosteum.

\section{Methods}

1) 2 Cases of isolated Group - 2 cleft palate in which Wardill-KilnerVeau pushback palatoplasty was used to repair the cleft palate. The nasal layer breached during dissection and suturing leaving a big rent in the nasal lining. Hence, repair of nasal lining at the junction of hard and soft palate could not be achieved. The two mucoperiosteal flaps were intact. The nasal mucosa was reconstructed by flipping the left mucoperiosteal flap. With mucosa facing nasal cavity flap was sutured to the bony palate. On top of this layer the right mucoperiosteal flap was transposed and sutured to create the oral mucosal layer (Figures 1 and 2). Thus we could achieve reconstruction of both nasal and oral mucosal layers with the two mucoperiosteal flaps at the critical junction soft and hard palate.

2) Three patients had minor salivary gland tumor at junction of hard and soft palate and one had carcinoma buccal mucosa excised. The lesion extended on to the pedicle of mucoperiosteal flap on one side. In these cases one half of the mucoperiosteal flap based on the greater palatine artery was used to resurface the defect on the other side of the palate.

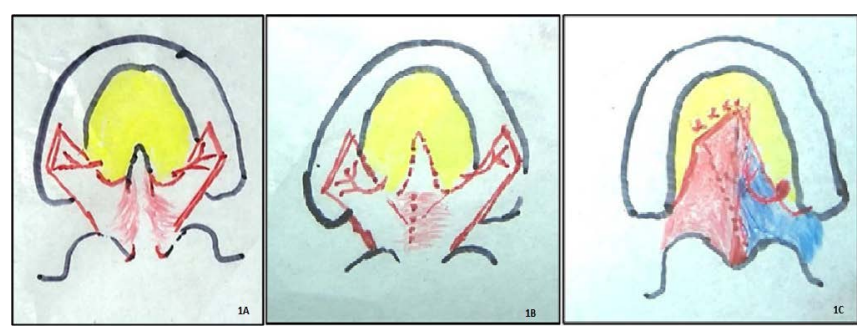

Figure 1: A) Cleft palate (both sides mucoperiosteum elevated); B) rent in the nasal lining; C) left mucoperiosteal flap used for nasal lining and right for buccal lining.

3) Four patients had buccal mucosal defect following excision of early malignancy and benign lesion. In these patients mucosa was replaced with free grafts (Mucoperiosteal) from the intact palate. The free mucoperiosteal graft took very well and functioned as mucosa after the wound healed (Tables 1 and 2).

\section{Results}

Pedicled flaps as well as free grafts healed very well without any morbidity. Palatal donor site healed by epithelisation and had no further deformity. Initially when pedicled flap was used, there was speech disturbance which improved later. Maximum defect size covered was $4 \times 4 \mathrm{cms}$.

\section{Discussion}

Palate is a complex structure. On either side of palate, there are cavities which have major functions (Nasal cavity- speech, oral cavity

${ }^{*}$ Corresponding author: Dr. Manjunath $\mathrm{KN}$, Department of Plastic and Reconstructive surgery, Ramaiah Medical College, M S Ramaiah Nagar, Bengaluru 560054, Karnataka, India, Tel: 9535971056; E-mail: drknmanjunath@gmail.com

Received: May 02, 2017; Accepted: June 07, 2017; Published: June 14, 2017

Citation: Manjunath KN, Waiker VP (2017) Mucoperosteum of the Palate - An Ideal and Versatile Reconstructive Tool. Reconstructive Surgery and Anaplastology 6 : 167. doi: 10.4172/2161-1173.1000167

Copyright: (c) 2017 Manjunath KN, et al. This is an open-access article istributed under the terms of the Creative Commons Attribution License, which permits unrestricted use, distribution, and reproduction in any medium, provided the original author and source are credited. 

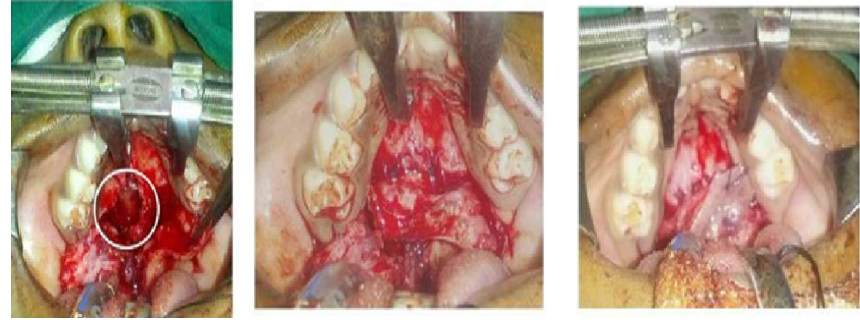

Figure 2: A) Dehiscence of nasal mucosal lining; B) left side mucoperiosteal flap in-turned; C) right mucoperiosteal flap draped over.

\begin{tabular}{|c|c|c|c|}
\hline \multicolumn{4}{|c|}{ Free grafts } \\
\hline Diagnosis & Site & Defect size(cms) & Result \\
\hline Carcinoma in situ & Floor of mouth & $3 \times 3$ & $\begin{array}{c}\text { No } \\
\text { necrosis }\end{array}$ \\
\hline Post traumatic loss & Upper alveolus & $4 \times 4$ & $\begin{array}{c}\text { No } \\
\text { necrosis }\end{array}$ \\
\hline Post Ranula excision & Lower lip & $3 \times 4$ & $\begin{array}{c}\text { No } \\
\text { necrosis }\end{array}$ \\
\hline Post excision & Left check mucosa & $3 \times 5$ & $\begin{array}{c}\text { No } \\
\text { necrosis }\end{array}$ \\
\hline
\end{tabular}

Table 1: Defect size, site and reconstructive procedure utilised.

\begin{tabular}{|c|c|c|c|}
\hline \multicolumn{4}{|c|}{ Pedicled flap } \\
\hline Diagnosis & Site & $\begin{array}{c}\text { Defect } \\
\text { size }(\mathrm{cms})\end{array}$ & Mucoperiosteal flap \\
\hline Cleft palate & Nasal lining & $2 \times 1$ & $\begin{array}{l}\text { Right side used for oral lining } \\
\text { Left side used for nasal lining }\end{array}$ \\
\hline Cleft palate & Nasal lining & $1 \times 1$ & $\begin{array}{l}\text { Right side flap used for oral } \\
\text { lining } \\
\text { Left side flap Used for nasal } \\
\text { lining }\end{array}$ \\
\hline $\begin{array}{c}\text { Carcinoma } \\
\text { buccal mucosa }\end{array}$ & $\begin{array}{l}\text { Right nasal } \\
\text { cavity }\end{array}$ & $3 \times 5$ & $\begin{array}{l}\text { Left side mucoperiosteum flap } \\
\text { used for reconstruction }\end{array}$ \\
\hline $\begin{array}{l}\text { Minor salivary } \\
\text { gland tumor }\end{array}$ & $\begin{array}{l}\text { Left half of } \\
\text { palate(Junction } \\
\text { of hard and soft } \\
\text { palate on right } \\
\text { side) }\end{array}$ & $3 \times 3$ & $\begin{array}{l}\text { Mucoperiosteum flap elevated } \\
\text { on left greater palatine artery }\end{array}$ \\
\hline $\begin{array}{l}\text { Recurrent } \\
\text { lesion }\end{array}$ & $\begin{array}{c}\text { Left upper } \\
\text { alveolus(Post } \\
\text { excision with } \\
\text { maxillary antrum } \\
\text { exposed) }\end{array}$ & $3 \times 2$ & $\begin{array}{l}\text { Mucoperiosteum flap elevated } \\
\text { on right greater palatine artery }\end{array}$ \\
\hline $\begin{array}{l}\text { Minor salivary } \\
\text { gland tumor }\end{array}$ & $\begin{array}{l}\text { Right half of } \\
\text { palate }\end{array}$ & $2 \times 2$ & $\begin{array}{l}\text { Mucoperiosteum elevated on } \\
\text { left greater palatine artery }\end{array}$ \\
\hline
\end{tabular}

Table 2: Diagnose size, site and mucoperiosteum flap.

-speech and mastication). The separating structure has thin bone, covered on either side by mucosa anteriorly. As we move posterior the rigid hard palate becomes dynamic soft palate. The buccal mucosa as a graft donor site is very versatile, as it heals on its own and leaves no deformity. Because of high vascularity of the mucosa, it can be harvested as free graft or pedicled flap. Cheek mucosa can only be harvested as free graft. Soft palate is a dynamic -muscular palate $[2,3]$ this dynamicity is hampered if the graft is harvested and mucosa is scarred [4]. However, the mucoperiosteum of hard palate is supplied by greater palatine artery and also highly vascular. In view of its vascularity it can either be harvested as a free graft or pedicled flap.

\section{Pedicled flaps}

The use of pedicled mucoperiosteal flap was first described by Millard for cleft palate repair [5]. The Greater palatine artery entering the mucoperiosteum at the palatine foramen forms the major supply and one pedicle can sustain most of the mucoperiosteum over the palate [6]. It can be harvested as peninsular or as island flap.

In two of our cases of complete cleft of secondary palate, WardillKilner-Veau(V-W-K) repair was planned. The elevated nasal mucosa during suturing breached and resulted in fistula at the junction of hard and soft palate. The thinness of nasal mucosa and less tonicity makes it very difficult to suture and as literature shows fistula is inevitable in inexperienced or even in case of experienced surgeons [7]. Creating a good nasal lining is an important step in cleft palate repair and double layered closure is the mainstay for a successful cleft palate repair [7]. Every effort should be given to create tough nasal mucosal layer. On table nasal mucosal fistula as a small perforation can be left alone to contract and heal but if large, then a salvage procedure to recreate nasal lining is a mandate. Variety of flaps has been used as salvage procedure. Ipsilateral vomerine flap is one. Buccal mucosal flap [8] is another choice. But in our case, since the vomerine flap was small we used one side palatine mucoperiosteal flap for nasal lining and other for oral lining. Both the flaps used to create palatal separation healed without complication and had good speech outcome with a follow up of six months. In two of our cases of salivary gland tumour, post excision defect was situated at the junction of hard and soft palate. In one case the challenge was to recreate the mucosal lining without altering soft palate function. Here we used the whole of mucoperiosteal islanded flap based on one greater palatine artery to cover the area. The advantage of local mucoperiosteal flap is its vascularity, adequate availability and location. The vascular capillary network (Vascular macronets described by Meher) allows [8] whole of the mucoperiosteum to be elevated based on one Greater palatine artery and also as islanded pedicle flap. Some studies have described palatal flap as big as $16.5 \mathrm{cms}[1,2]$. The donor site heals completely in 2-3 weeks without contractures or compromising function of the palate $[9,10]$. Islanded mucoperiosteal flap invented by Guelle-Arena [11] in 1977, used for palatal reconstruction has $95 \%$ success rate. But the posterior reach of islanded palatine flap is difficult, due to the bony canal through which the pedicle emerges. But breaking the posterior wall of the palatine foramina makes further reach possible.

\section{Free grafts}

Free graft in our case was used for small defects following excision of lesion in situ where the maximum mucosal defect was $3 \times 4 \mathrm{~cm}$. Small defects in oral cavity can be left alone for secondary healing or skin grafted. However these have disadvantages like unpredictable contracture, initial malodorous discharge and pooling of saliva [12]. Free mucoperiosteal graft has the advantage of being local tissue and hence it does not leave any other donor area morbidity. The donor site heals well by epithelisation and needs no other cover procedure. Elevation of grafts in growing children is known to hamper growth of palatal shelves. In our adult patients there was no donor site morbidity. Free graft has been used in recalcitrant pharyngeal wall stenosis [13], the results of which were superior to skin grafts or buccal mucosal grafts, as skin grafts resulted in secondary contracture and the area had less pliability. Whereas in studies which used mucoperiosteal flap did not result in donor site deformity and the defects were recreated with native tissue [14-16]. But the limitation is the size of graft available. Larger defects definitely need distant/regional flap. In all our cases there was no flap loss or necrosis. Even in free grafts we had excellent outcome and there was absolutely no donor site deformity.

\section{Conclusion}

Palate is a complex structure both functionally and anatomically. Successful reconstruction of palatal defects depends on creation of good 
Citation: Manjunath KN, Waiker VP (2017) Mucoperosteum of the Palate - An Ideal and Versatile Reconstructive Tool. Reconstructive Surgery and Anaplastology 6: 167. doi: 10.4172/2161-1173.1000167

Page 3 of 3

nasal as well as buccal mucosal lining. The rich vascular macro net in the palatal mucosa makes it an ideal donor site for local reconstruction. The mucoperiosteum harvested either as a free graft or as pedicled flap serves the purpose well leaving no donor site deformity. However, size available for harvesting is limited and larger defects definitely need distant flap. But, for smaller defects palatal mucoperiosteum, harvested either pedicled flap or free grafts, is indeed an ideal reconstructive tool.

\section{Conflict of Interest}

None

\section{References}

1. Kim HY, Hwang J, Lee WJ, Roh TS, Lew DH, Yun IS (2014) Palatal mucoperiosteal island flaps for palate reconstruction. Arch Craniofac Surg 15: 70-74.

2. Maistry T, Lazarus L, Partab P, Satyapal KS (2012) An anatomical study of the arterial supply to the soft palate. Int J Morphol 30: 847-857.

3. Fritzell B (1969) The velopharyngeal muscles in speech. Acta Oto-Laryngo 250: 1 .

4. Millard DR (1962) Wide and/or short cleft palate. Plast Reconstr Surg Transplant Bull 29: 40-57.

5. Maher WP (1977) Distribution of palatal and other arteries in cleft and non-cleft human palates. Cleft Palate J 14: 1-12.

6. Tunçbilek G, Konaş E, Ozgür F (2007)A salvage procedure in cleft palate repair Suturing nasal mucosadirectly to palatine process. Cleft Palate Craniofac J 44 :
233-234.

7. Jackson IT, Moreira-Gonzalez AA, Rogers A, Beal BJ (2004) The buccal flap--a useful technique in cleft palate repair? Cleft Palate Craniofac J 41: 144-151.

8. Ward BB (2003) The palatal flap. Oral Maxillofac Surg Clin North Am 15: 467473.

9. Hakato M, Tada H, Shirai T (1995) Usefulness of hard palate mucosa graft as nasal lining in alar reconstruction. Plast Reconstr Surg 95: 390-395.

10. Genden EM, Lee BB, Urken MLm (2001) The palatal island flap for reconstruction of palatal and retromolar trigone defects revisited. Arch Oto larynol Head Neck Surg 127: 837-841.

11. Panje WR (1987) Immediate reconstruction of the oral cavity. In: Thawley SE, Panje WR (eds). Comprehensive Management of Head and Neck Tumors. Saunders, Philadelphia. pp: 544-563.

12. Kerner MM, Dulguerov P, Markovitz BL, Berke GS (1994) Reconstruction of a hypopharyngealdefect with a palatal mucoperiosteal graft. Am J Otolaryngol 15: $370-374$.

13. Hall HD, O'Steen AN (1970) Free grafts of palatal mucosa in mandibular vestibuloplasty. J Oral Surg 28: 565-574.

14. Siegel RJ (1985) Palatal graft for eyelid reconstruction. Plast Reconstr Surg 76: 411-414.

15. Yoshimura Y, Nakajima T (1990) Tracheosplasty with palatal mucoperiostea graft. Plast Reconstr Surg 86: 558-560.

16. Nakajima T, Yoshimura $Y(1990)$ Secondary correction of bilateral cleft lip nose deformity. J Craniomaxillofac Surg 18: 63-67. 